\title{
Using Artificial Intelligence in energy efficient construction
}

\author{
Arkadiusz Węglarz ${ }^{1, *}$ \\ ${ }^{1}$ Faculty of Civil Engineering, Warsaw University of Technology, Warsaw, Poland
}

\begin{abstract}
Artificial Neural Networks (ANNs), genetic algorithms, case based reasoning (CBR), and hybrid systems are all methods of artificial intelligence. This dissertation presents a literature overview and its author's achievements in methods of utilizing artificial intelligence methods in energy efficient buildings, which include: an expert system for supporting the financing of thermo-modernization investment, a method of optimizing thermo-modernization strategies for groups of buildings using genetic algorithms, and a case based reasoning system (CBR) intended to facilitate the design of energy efficient single family housing. Case based reasoning consists of comparing new problems with past problems and using a past solution. In the CBR system, previously developed single family housing designs will be described using linguistic variables defined as fuzzy sets. The designer, who wants to create the documentation for a new energy efficient building after talking with the investor about his or her expectations, enters a query, defined as linguistic variables, into the system. The system finds the documentation of already constructed buildings, most closely matching the investor's requirements. The designer performs the required adjustments, and after the investor's approval, places the new documentation into the database for further use.
\end{abstract}

\section{Introduction}

The building sector contributes to a large part of the global energy consumption and has a permanent detrimental effect on the natural environment [1-4]. Due to this, over the last couple of decades, scientists all over the world have been working on solutions which will change this situation [1-26]. Significant energy savings can be achieved by appropriately designed and operated buildings. In turn, it is difficult to imagine the design, construction, and operation of a building without the use of adequate tools and computer methods. Many of these tools have been described in Polish and foreign literature [1-6], [12-14], [17-27]. Out of modern research tools, particular attention should justly be given to artificial intelligence (AI) [1-2], [12-13],[18-23],[25-27] . The most commonly applied AI methods include: genetic algorithms, expert systems, case based reasoning (CBR), and hybrid systems. Presented below are examples of utilizing AI in energy efficient buildings.

${ }^{*}$ Corresponding address: a.weglarz@pw.edu.pl 


\section{Al utilized in energy efficient buildings}

The leading problem of designing and operating energy efficient buildings is the forecast of energy demand. For many years, this problem has been primarily solved through engineering simulations. Many computer programmes have been developed over the years, such as: DOE-2, ESP, Energy Plus, and DeST (Designer's Simulation Toolkit) [1]. Despite accurately forecasting the energy demand of the building, in many cases, the forecasts vary depending on the programme. Creating simulation models is complicated and workintensive, due to the employment of knowledge from many disciplines, and the large range of values for setting parameters dependent on the building's operation profile. The use of current tools for simulating the energy performance of buildings is also difficult to identify and compare the influence of variables on the observed parameter value constituting the assessment of the building's internal climate [1]. For this reason other methods of forecasting energy demand in buildings are being developed.

The literature proposes many AI techniques meant to improve the accuracy of forecasting the energy consumption of buildings. For example Li et al. proposed a hybridized genetic algorithm with an adaptive network - based on fuzzy inference system [1-2]. Tsanas and Xifara used the random forest (RF) technique to estimate the demand for heating and cooling in residential buildings [3]. Other techniques of machine learning proposed in the literature used for forecasting energy demand are: support vector regression (SVR), artificial neural network (ANN), classification and regression tree (CART), chi squared automatic interaction detector (CHAID), general linear regression (GLR) and hybridized systems [1]. The newest research (began in 2012) indicate the use of ensemble systems utilizing the above mentioned machine learning methods [1-2]. In machine learning, an ensemble model is defined as an approach utilizing many algorithms to obtain better predictive performance, than those achievable by any of the constituent learning algorithms [1].

Systems facilitating the design of a building's architecture and construction are an important area of utilizing AI in the building sector. Expert and CBR systems play a leading role [1], [17-19]. The development of the methodology of knowledge representation means that computer programmes can be constructed in a way which helps the designer in choosing construction materials and systems. Databases within these expert systems contain information on the regulatory requirements of building energy efficiency, the methods and technologies of achieving defined energy standards and are connected to databases of material properties. This allows the designer to solve the information processing problem and the automatic analysis of many alternative solutions.

Another group of problems concerning the energy efficiency of buildings in which AI techniques are used is the operation of heating, ventilation and air conditioning systems (HVAC), damage diagnostics and its modeling [20-22]. In this regard the focus is placed on solutions pertaining to heating comfort, visual comfort, and internal air quality, simultaneously with energy savings. The following are used for modelling these problems: neural networks, fuzzy logic, genetic algorithms, and expert systems. Managing energy in intelligent energy efficient buildings is also an area in which artificial intelligence is used [1-2]. This particularly concerns assessing the behaviour of the building's user, which is necessary for the appropriate regulation of a building's technical systems [23-24].

Due to their ease of use and the ability to adapt to the quickly required optimal solution, AI approaches gained popularity in recent years. It is worth it to more closely examine some of these techniques. 


\section{Expert system supporting the financing of thermomodernization investments in buildings}

An expert system supporting the financing of thermo-modernization investments in buildings consists of the following four databases, constructed based on available information sources:

- Database of potential investors,

- Database of thermo-modernization measures,

- Database of companies providing energy services ( ESCO/TPF),

- Database on legal regulation regarding contracts and tenders.

The above mentioned databases are prepared by the system's designer based on existing databases or available information on the market. Each of the listed databases is updated with application rules and only then it can be considered a knowledge database. The aim of the system is finding a partner for an investor desiring to undertake a particular thermomodernization measure from among the energy service companies (ESCO/TPF).

After entering information concerning the investors legal form (which plays a role in the estimated financial flow, due to tax leveraging and tender issues), the investor defines the type of building, and the thermo-modernization measure he or she would like to undertake.

Next the system accesses the knowledge database created from the database of verified energy audits supplemented with the requirements of a database and ranks the measures by internal rate of return and payback period. These two data points are the basis for searching the knowledge database for investment companies, which declared similar financing terms and interest. The result is a list of companies with which the investor can negotiate the implementation of the measure. The expert system also provides the investor with answers to the following questions:

- What should I do?

- How much will it cost?

- What are the potential savings?

- Who can help me?

- What is the most favourable investment structure?

- What should the tender documentation contain?

- What should the contract with the chosen ESCO/TPF contain?

- How to guarantee a possibility of verifying the achievement of the results?

A scheme for an expert system is shown in Fig. 1.

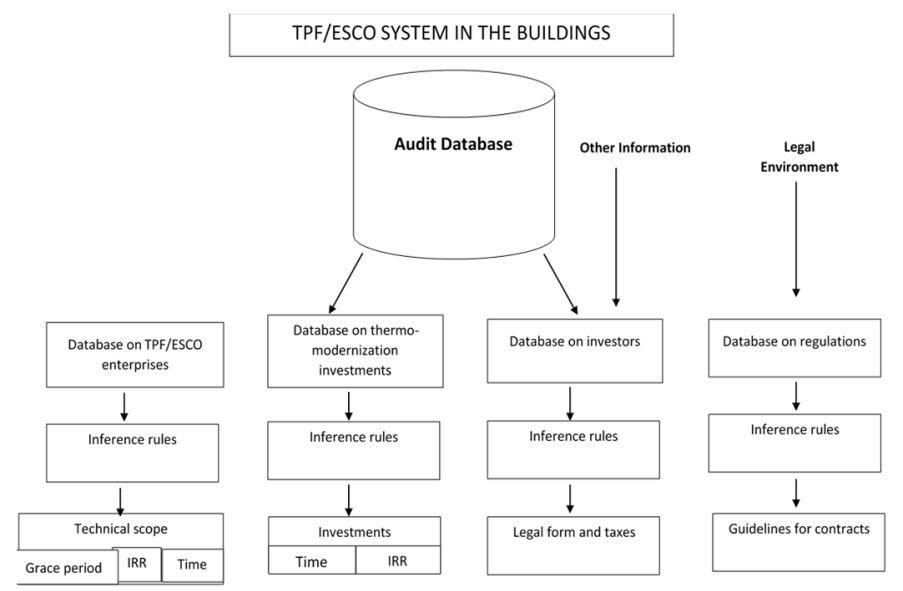

Fig. 1. Scheme for an expert system supporting financing of thermo-modernization investments in buildings. Source: KAPE S.A.. 


\section{Method of optimizing thermo-modernization strategies for groups of buildings}

The method of optimizing thermo-modernization strategies for groups of buildings solves the problem of setting a schedule and scope for modernizations in a group of buildings (min. 10), so that the entire undertaking is completed in the shortest time, with a set initial size of the modernization fund [12].

The basic method of optimizing thermo-modernization strategy of a housing complex is the autonomous repayment principle. It relies on using the investor's available resources to first perform the modernization of a building, which has the shortest repayment period. The modernization of the remaining buildings is financed from the cost of energy consumption saved by the modernized buildings. The problem with making a decision consists of setting a schedule and at what time set buildings should be renovated, as to finish the investment process as quickly as possible, at the lowest possible cost, and the available starting level of financial resources from the renovation fund. The method of designating the optimal thermo-modernization strategy is based on a digital static simulation and genetic algorithms, which are commonly considered a modern tool for finding optimal solutions using the iteration method. The investment process for a single building is divided into 5 stages corresponding to the types of acceptable thermomodernization measures (insulating walls, replacing windows, etc.). For each stage of the building's investment process an assumption was made as to the effectiveness of a work crew, which served as the basis for calculating the time required to complete the task. Energy savings were chosen as the random factor, which to a large extent, depend on the "number of degree days" parameter. This value is characterized by weather changes in the heating season. It was assumed that the "number of degree days" parameter is described by a regular distribution with a standard value and a standard deviation calculated using perennial weather data for a particular local. After knowing the standard deviation and the average probability distribution of the "number of degree days" parameter value, a series of statistical experiments can be performed. In each experiment, potential energy savings for a particular building are chosen based on the value of the "number of degree days" parameter drawn from a standard distribution, and next, using a genetic algorithm the schedule of the modernization of each building, the total investment duration, the total investment cost, and the necessary starting sum ensuring investment liquidity is determined. The algorithm described above was programmed in Visual Basic. It was tested using a group of 30 residential, municipal buildings in Legionowo. Based on the results of this programme the development of a thermo-modernization strategy for 30 residential, municipal buildings was developed. As a result of the conducted duration-cost analysis it was established, that the modernization of four of the buildings is unviable; due to a too long return period [12]. The research conducted allow the conclusion that utilizing refined optimization methods, such as combining digital simulation with genetic algorithms, to seemingly trivial problems of establishing an investment schedule has its purpose.

\section{Case based reasoning (CBR) system intended to facilitate the design of energy efficient single family housing}

Case based reasoning (CBR) consists of comparing a new problem to a problem encountered before, and using the past solution [25-26].

The concept of a case based reasoning (CBR) system intended to facilitate the design of energy efficient single family housing was created as result of a questionnaire study conducted among architects. In the study the architects were asked in what way do they understand terms such as: a small house, a small bedroom, a large house, a residence, 
a medium garage, etc. Investors were asked the same questions. The architects and the investors were tasked with defining these terms determining the range of variance in usable space, and the size of each room. For example, respondents were asked to complete the following task:

Please define the term:

- A small, single bedroom is a room with a usable floor area: from..... to ..... and a standard measurement of: .......m/......m;

- A medium, single bedroom is a room with a usable floor area: from..... to ..... and a standard measurement of: ........m/......m;

- A large, single bedroom is a room with a usable floor area: from..... to ...... and a standard measurement of: ..m;

- A huge, single bedroom is a room with a usable floor area: from..... to ..... and a standard measurement of: $\mathrm{m} / . \ldots \ldots . \mathrm{m}$.

Linguistic variables were defined based on the results of 20 questionnaires. The linguistic variables are represented by four data points (x, T(x), U, MN ), where:

- $x-$ is the name of the linguistic variable, e.g. "Size of a single bedroom",

- $\mathrm{T}(\mathrm{x})$ - is a set of linguistic values of the $\mathrm{x}$ variable, that is, a textual description of values which the linguistic variable takes on e.g $\mathrm{T}(\mathrm{x})=$ (small, large, huge, etc.),

- $\mathrm{U}$ - the numerical domain of the variable, so a range of numerical values, which a given linguistic variable can take on, e.g. $\mathrm{U}=[6 ; 125] \mathrm{m}^{2}$ usable floor area,

- $\mathrm{MN}$ - rule of assigning the linguistic variable to fuzzy sets.

The method of assigning a linguistic variable to fuzzy sets chosen was describing the values of the linguistic variable e.g. "small (single bedroom") with trapezoidal fuzzy numbers e.g. $A=\left(a_{1}, a_{2}, a_{3}, a_{4}\right)$. The $a_{1}$ value is equal to the smallest usable floor area given by the respondents for a small (single bedroom). The value of the $<\mathrm{a} 2, \mathrm{a} 3>$ range is the area range given by all respondents. The $\mathrm{a}_{4}$ value is equal to the highest usable floor area given by all respondents. The method of describing the "small (single bedroom) linguistic value using a trapezoidal fuzzy numbers is given in Fig. 2. An example of the value for the "large" linguistic variable: "Large single bedroom" described using trapezoidal fuzzy number $A=(14,16,20,25)$ is shown in Fig. 3 .

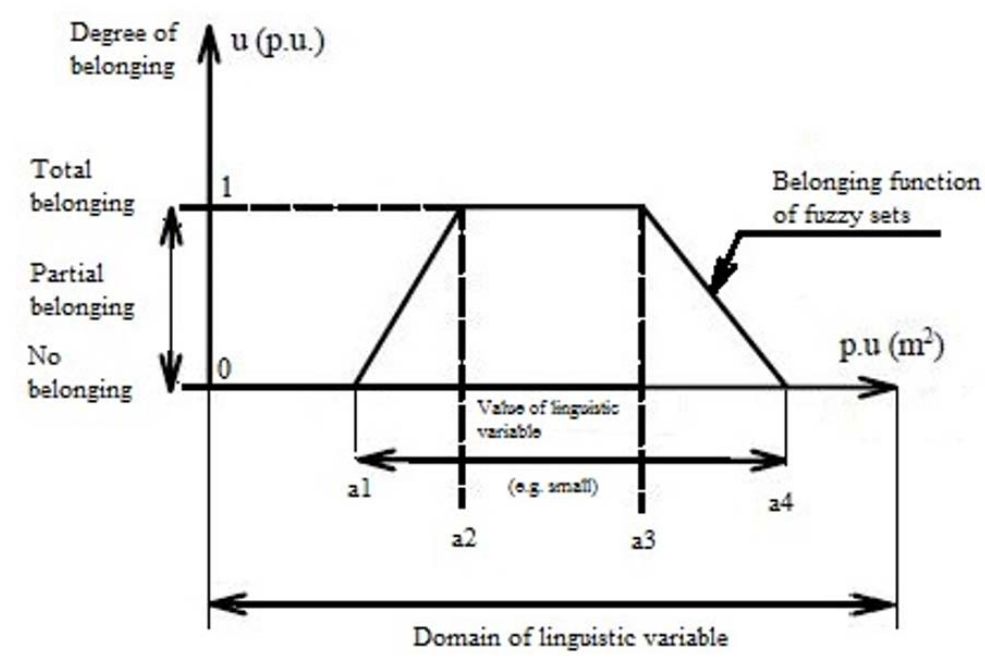

Fig. 2. The method of creating trapezoidal fuzzy numbers describing the value of linguistic variables. Own elaboration. 
Where: p.u - usable area.

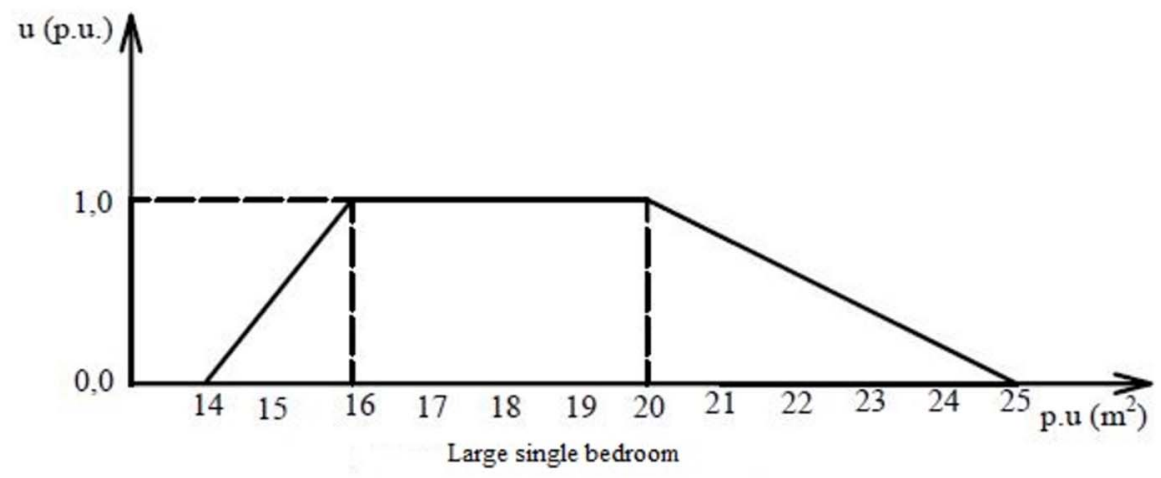

Fig. 3. Example of a description of "large" using trapezoidal fuzzy numbers for the "Size of single bedroom" linguistic variable.

In the CBR system, earlier single family house designs will be described in a database using linguistic variables created through the above mentioned algorithm. An exemplar description of a project in the CBR system is show in Table 1. The designer who wants to create the documentation of a new energy efficient building after talking with the investor about his or hers expectations enters a question using the linguistic variable into the system The knowledge base of the expert system contains the rules and basic facts necessary for defining the investor's requirements with respect to the architectural concept. Moreover, the knowledge base contains rules verifying whether the investor submitted complete data (facts) necessary for developing an architectural concept and the possibility of automatically correcting the data to achieve the desired floor area and function. Based on the question prepared using the expert system, the CBR system searches its own database for documentation of already existing buildings closely congruent with the investor's requirements, while simultaneously giving the degree of agreement (probability) of the results with the question. The designer chooses the documentation with the highest probability, performs the necessary adjustments arising from the investor's expectations, passes the new documentation to the investor and enters it into the database for further use. The literature describes many measures of agreement [25-27]. For the needs of this CBR system the simplest one was chosen, that is a count of CBR answers in agreement with the investor's expectations. In the first stage it searches for all projects in which the value of the "Size of the house" linguistic variable agrees with the value of the variable defined in the question of the CBR system. As an example, we are searching for a "small" house. In the next stage the agreement of the remaining linguistic or numerical variables are checked for agreement. For each design of a "small" house the system counts the number of linguistic or numerical variables in agreement with the question of the CBR system.

The result with the highest value of agreement between the CBR answer and the investor's expectations is chosen as the one with the highest degree of probability (the design to be adapted by the architect). 
Table 1. An example of a building's description in the CBR system.

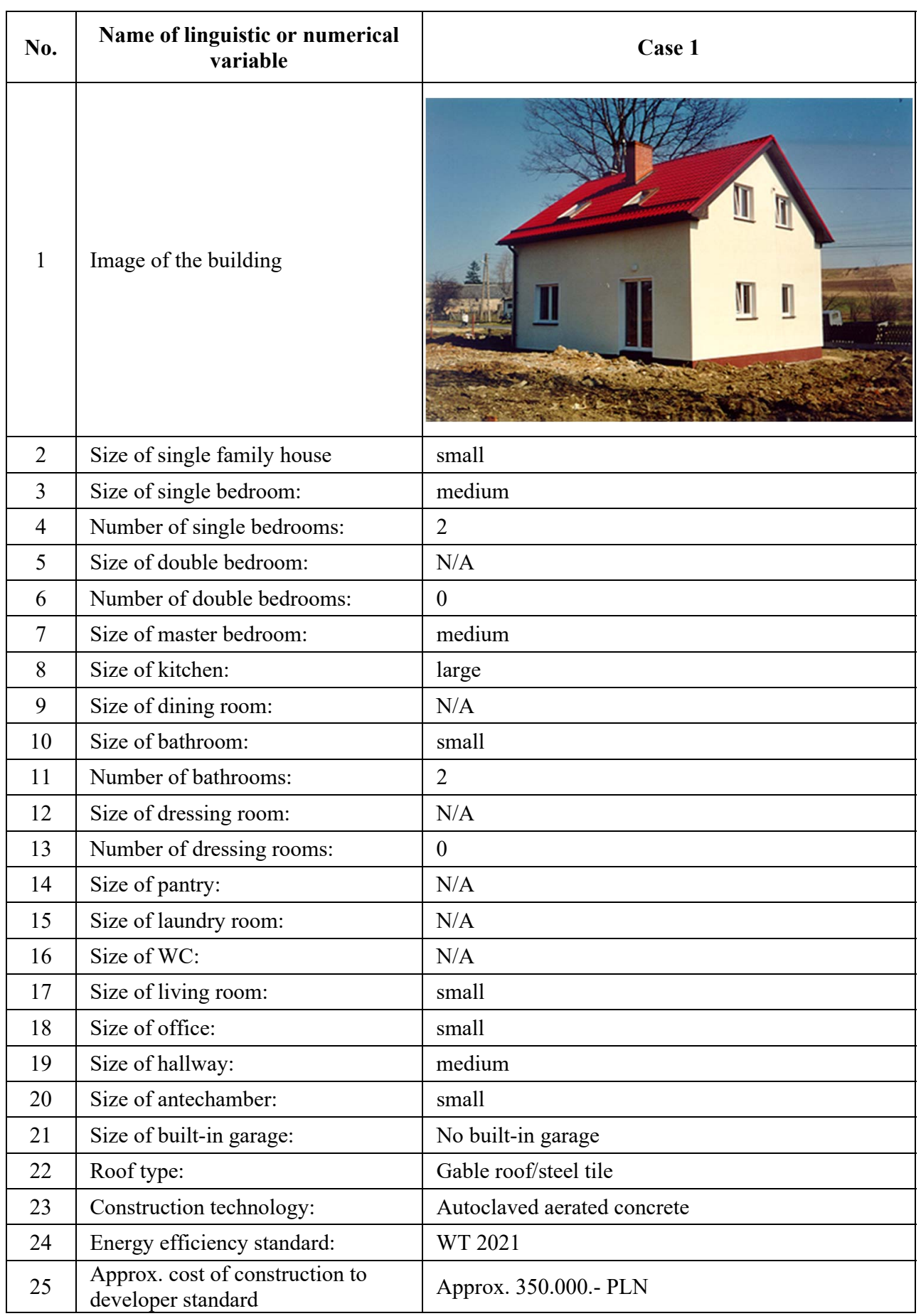




\section{Summary and conclusions}

The following elaboration presented examples of utilizing artificial intelligence in energy efficient buildings. The research conducted allows the conclusion that its use in this field is justified.

A broad analysis of the literature [1], [2], [6], [13], shows that an accurate forecast of a building's energy demand during the design stage can aid proper operation of its technical systems (including energy systems). In turn, this affects the improvement of the user's comfort, longer life cycle of technical equipment and their energy efficiency, as well as lowering the building's operation costs. Artificial intelligence allows performing quick and accurate energy demand forecasts, and in real mode can serve as the basis for efficient management of a building's energy.

Utilizing AI during the building's design process offers very good results by reducing the time required for analyses of different architectural and technological concept variants in energy efficient buildings.

Using the proposed AI methods as tools for designing and analysing energy efficient buildings can play an important role in increasing the energy efficiency in the construction sector.

Artificial intelligence methods facilitate solving a fundamental problem of the Polish energy efficient construction sector, which is having participants of the investment process lacking the appropriate knowledge.

The research and application of artificial intelligence methods will be continued and developed towards supporting decision making in the entirety of the investment process and in determining the behaviour of participants of said process (particularly the users of buildings on improving energy efficiency in the construction sector).

\section{References}

1. Z. Wang and R. S. Srinivasan, Renew. Sustain. Energy Rev., 75, no. September 2015, 796-808, (2017)

2. J. S. Chou and D. K. Bui, Energy Build., 82, 437-446 (2014)

3. A.-T. Nguyen, S. Reiter, and P. Rigo, Appl. Energy, 113, 1043-1058 (2014)

4. R. Pacheco, J. Ordóñez, and G. Martínez, Renew. Sustain. Energy Rev., 16, no. 6, 3559-3573 (2014)

5. M. Nilashi et al., Knowledge-Based Syst., 86, pp. 194-209, (2015)

6. D. Coakley, P. Raftery, and M. Keane, Renew. Sustain. Energy Rev., 37, pp. 123-141, (2014)

7. S. Firląg, Procedia Engineering 111, 202-208, (2015)

8. S. Firląg, Czasopismo Techniczne. Budownictwo 107 (2-B), str. $49-57$ (2010)

9. W. R. Terlikowski, MATEC Web of Conferences, vol. 117, str. 1-8 DOI:10.1051/matecconf/201711700165, (2017)

10. D. Heim, Renewable Energy, 35, Issue 4, Pages 788-796, ISSN 0960-1481. doi:10.1016/j.renene.2009.09.005, (2010)

11. A. Kaliszuk-Wietecka, Budownictwo zrównoważone. Wybrane zagadnienia z fizyki budowli, (Wydawnictwo Naukowe PWN, ISBN 9788301188368, 2017)

12. P. Sadowski, A. Węglarz, Polska Energetyka Słoneczna 3 (4), str. 32-36, (2006)

13. P. Malinowski, P. Ziembicki, Journal of Civil Engineering and Management 12.1/2006, 21-28., (2006) 
14. M. Klimczak, J.Bojarski, P. Ziembicki i P. Kęskiewicz, Energy Build. 169, 141-147 (2018)

15. M. Piasecki, K. Kostyrko, S. Pykacz, J. Build. Phys. 41: (3), 294-289 (2017)

16. M. Piasecki, K. Kostyrko, J. Build. Phys., vol. 5, DOI: 10.1177/174425911875439, (2018)

17. S. Mazouz and M. Zerouala, Energy Build., 33(7), 699-710 (2001)

18. D. R. Rehak, S. J. Steven, and J. Fenves, Expert systems in civil engineering, construction and construction robotics, 1-29 (1984).

19. A. Berrais, Expert Syst. Appl., 28, (3), 519-530 (2005)

20. S. Soyguder and H. Alli, Energy Build., 41, (8), 814-822 (2009)

21. Z. Şen, Expert Syst. Appl., 37, no. 8, 5653-5660 (2010)

22. A. I. Dounis, Adv. Build. Energy Res., 4, (1), 267-299 (2010)

23. S. D’Oca, T. Hong, and J. Langevin, Renewable Sustainable Energy Rev., 81 (2018)

24. T. Hong, D. Yan, S. D’Oca, and C. fei Chen, Build. Environ., 114 (2017)

25. S. Zbroja, A. Ligęza, Proc. Int. Conf. Syst. Sci., 2, (2001)

26. A. Kempa, Technologia przetwarzania wiedzy w SWO, 283-290 (2007)

27. M. Meler-Kapcia, Logistyka, 4, 7244-725 (2014) 